\title{
The effect of Thymbra spicata extract and its bioactive component Thymol on non-small-cells lung cancer cell line A549
}

\section{Type}

Research paper

\section{Keywords}

lung cancer, Apoptosis, HPLC, thymol, Thymbra spicata

\begin{abstract}
Introduction

Alternative medicine is important in cancer treatment. The apoptotic effect of Thymol and extracted Thymol from Thymbra spicata on non-small-cells lung cancer was studied.
\end{abstract}

Material and methods

Thymol was evaluated in Thymbra spicata extract by HPCL. Cell viability was assessed by MTT method. DCF and flu3-AM probe was used for ROS and cai2+ analysis, respectively. Western blotting was performed to measure NOX2 and Bax/Bcl-2 ratio.

Results

Obtained data showed that Thymol was $1.51 \mathrm{mg} / \mathrm{g}$ in Thymbra spicata extract. Treatment with Thymol and extracted Thymol from Thymbra spicata resulted in cell death at high concentrations [LC50 $=111 \pm 4.5$ and $119 \pm 5.2 \mu \mathrm{M}$, respectively]. Subsequently, Thymbra spicata extract and its bioactive component increased ROS and Cai2+ production, NOX2, and Bax/Bcl-2 ratio.

\section{Conclusions}

This study revealed the anticancer effects of Thymol and Thymbra spicata extract on non-small-cells lung cancer and at least part of that effect was related to the increase in the NOX2 and Bax/Bcl-2 ratio. Our results demonstrated that TSE and Thymol at high concentrations $(180,120$, and $80 \mu \mathrm{M})$ decreased the growth of $A 549$ cells. It appeared that cytotoxic activity was exerted through activation of NOX2, ROS generation, increase in Cai2+, and Bax/Bcl-2 ratio. Present results demonstrated that TSE and thymol may be potential therapeutic agents for human lung cancer. 

cells lung cancer cell line A549

3 Ardeshir Moayeri ${ }^{1}$, Shahram Mohammadpour ${ }^{1}$, Naser Abbasi ${ }^{2,3}$, Ali Aidy ${ }^{2}$, Elahe Karimi ${ }^{2 *}$, Hori Ghaneialvar ${ }^{2,4 *}$

$5{ }^{1}$ Department of Anatomy, Medical School, Ilam University of Medical Sciences, Ilam, Iran

$6 \quad{ }^{2}$ Biotechnology and Medicinal Plants Research Center, Ilam University of Medical Sciences,

7 Ilam, Iran

$8{ }^{3}$ Department of Pharmacology, Medical School, Ilam University of Medical Sciences, Ilam, Iran

$9{ }^{4}$ Department of clinical biochemistry, faculty of medicine, Ilam University of Medical Sciences, 10 Ilam, Iran

11 Corresponding author: Elahe Karimi, Ph.D., Biotechnology and Medicinal Plants Research 12 Center, Medical School, Ilam University of Medical Sciences, Ilam, Iran, Tel: +98-84-3223081, 13 Fax: +98-84-32223081, E-mail: Karimi-e@medilam.ac.ir

14 Corresponding author: Hori Ghaneialvar, Ph.D., Department of clinical biochemistry \& Biotechnology and Medicinal Plants Research Center, Medical School, Ilam University of 16 Medical Sciences, Ilam, Iran, Tel: +98-84-3223081, Fax: +98-84-32223081, E-mail: 17 Ghaneialvar-h@medilam.ac.ir 


\section{Abstract}

25 Introduction: Alternative medicine is important in cancer treatment. The apoptotic effect of 26 Thymol and extracted Thymol from Thymbra spicata on non-small-cells lung cancer was 27 studied.

28 Material and methods: Thymol was evaluated in Thymbra spicata extract by HPCL. Cell 29 viability was assessed by the MTT method. DCF and flu3-AM probe was used for ROS and cai ${ }^{2+}$ 30 analysis, respectively. Western blotting was performed to measure $\mathrm{NOX}_{2}$ and $\mathrm{Bax} / \mathrm{Bcl}-2$ ratio. 31 Results: Obtained data showed that Thymol was $1.51 \mathrm{mg} / \mathrm{g}$ in Thymbra spicata extract. 32 Treatment with Thymol and extracted Thymol from Thymbra spicata resulted in cell death at 33 high concentrations [LC50=111 \pm 4.5 and $119 \pm 5.2 \mu \mathrm{M}$, respectively]. Subsequently, Thymbra 34 spicata extract and its bioactive component increased ROS and $\mathrm{Cai}^{2+}$ production, NOX2, and $35 \mathrm{Bax} / \mathrm{Bcl}-2$ ratio.

36 Conclusions: This study revealed the anticancer effects of Thymol and Thymbra spicata extract 37 on non-small-cells lung cancer and at least part of that effect was related to the increase in the NOX2 and Bax/Bcl-2 ratio.

39

40

41

42

43

44 45

46

keywords: Thymbra spicata, Thymol, Lung cancer, Apoptosis, HPLC. 


\section{$47 \quad$ Introduction}

48 One of the most widespread cancers which cause death is lung cancer [1]. Non-small cell lung cancer (NSCLC) is the most frequent type of cancer [2]. ROS (Reactive oxygen species) has a 50 significant role in the mitochondrial membrane depolarizing and this phenomenon to go causes

51 apoptosis [3]. There are several sources of intracellular ROS production such as the NADPH 52 (nicotinamide adenine dinucleotide phosphate) oxidase (NOX family) [4]. ROS production leads 53 to an increased Bax/Bcl-2 ratio which is one of the causes of apoptosis [5]. Chemotherapy drugs 54 such as cyclophosphamide, doxorubicin, and etoposide are used to treat NSCLC and small-cell 55 lung cancer [6]. Herbal medicines have a long history of being used in the treatment of cancer 56 and are a major source of new medicine. Even the ingredients of medicinal plants such as 57 vincristine obtained from the Vinca rosea and paclitaxel (Taxol) from the leaves of various 58 Taxus species have an important place in the treatment of cancer today [7].

59 Also, some medicinal herbs such as Cordyceps militaris, Selaginella tamariscina, and Crocus 60 sativus L. are traditional herbs with antimetastatic effects against lung cancer cells [8]. It has 61 been demonstrated that the active components of medicinal plants such as myricetin [9], 62 berberine [10], and luteolin [11] have shown anti- lung cancer effects.

63 Thymus species have been used as a group of medicinal plants to treat various diseases. 64 Monoterpene Thymol has been found in the oils of many medicinal plants, such as Thymus 65 ciliates, Trachyspermum ammi, Thymus vulgaris, Nigella sativa, Monarda fistulosa, and 66 Thymbra spicata [12]. It is known that Thymol activates apoptosis in a dose-dependent manner 67 in various cancers. Thymol uses to treat malignancies is newly appreciated while the mechanism 68 of apoptosis induction is unknown [13]. 
69 In this study, possible mechanisms of cell death in lung cancer were investigated in addition to

70 the identification of the active ingredient of Thymol in the Thymbra spicata plant.

\section{$71 \quad$ Material and methods}

\section{Thymbra spicata extraction and Thymol identification by HPLC}

73 The Thymbra spicata specimens were collected from the surrounding environment of Ilam, Iran,

74 in May 2019. The plant materials were authenticated by the Horticulture Department, School of 75 Agriculture, Ilam University (voucher specimens, 596). The plant's powder (25 g) was extracted 76 with water-methanol for $24 \mathrm{~h}$ by the soxhlet apparatus. Solvents were evaporated (rotary, 77 Germany, IKA HB 10). The extract percentage was $7.21 \%$, and after lyophilization, it was kept 78 stored in the freezer $\left(-20^{\circ} \mathrm{C}\right)$. Then, the dissolved samples in methanol were filtered by a syringe $79 \quad(0.22 \mu \mathrm{m})[14]$.

80 To detect Thymol, a reversed-phase high-performance liquid chromatography (Smart line; 81 Knauer, Germany) with a C18 HPLC Columns (Knauer, Nucleosil H.P., $100 \AA \AA$ pore size, 82 internal diameter $25 \mathrm{~cm} * 0.46 \mathrm{~cm}$, particle size $3 \mu \mathrm{m}$,) and a UV detector (Knauer, K-2600, 83 Well chrome) was calibrated. Mobile phase (methanol (A) and water with $0.1 \%$ formic acid (B) 84 at range from 5-70\%), column temperature $\left(25^{\circ} \mathrm{C}\right)$, injection volume $(1 \mu \mathrm{L})$, detection 85 wavelength $(284 \mathrm{~nm})$, and flow rate $(1 \mathrm{ml} / \mathrm{min})$ was set. The standard solution of Thymol was 86 injected under similar conditions. The obtained peak from the extract of Thymbra spicata (TSE) 87 was compared to the standard of Thymol. A prepared Thymol standard stock solution in 88 methanol $(0.1 \mathrm{mg} / \mathrm{ml})$ was diluted to obtain $5,10,20,40,80,120$, and $180 \mu \mathrm{M}$ [15].

\section{Cell culture}


90 The cells (A549) were cultured in Dulbecco's Modified Eagle Medium with 1\% antibiotic and

$9110 \%$ FBS. In an incubator at $37^{\circ} \mathrm{C}$, containing 5\% CO2 cells were incubated. Then, cells were

92 used between the 2 nd and the 5 th passages.

93 Cell viability assay

94 Cell viability and cytotoxic effects of different concentrations of TSE and Thymol were 95 evaluated by MTT. In this technique, the color change by mitochondrial dehydrogenases from 96 tetrazolium salt (yellow) to formazan crystals (purple) was considered [16]. Cells were cultured 97 with different concentrations $(5,10,20,40,80,120$, and $180 \mu \mathrm{M})$ of Thymol in TSE and free 98 Thymol. For 24, 48, and 72h, cells were incubated. Then, after MTT reagent (10 $\mu 1)$ addition, for

$994 \mathrm{~h}$ plates were incubated. Formazan was soluble with gentle shaking at $37^{\circ} \mathrm{C}$ in DMSO $(100$ $100 \mu \mathrm{L}$ ), and with an ELISA Plate Readers absorbance was read at $595 \mathrm{~nm}$ (USA, Molecular 101 Devices; Spectra MAX).

102 Assessment of ROS

103 To measure intracellular ROS levels, DCFH-DA (a fluorescent probe) was used [17]. The cells 104 were incubated with DCFH-DA $\left(10 \mu \mathrm{M}, 37^{\circ} \mathrm{C}, 30 \mathrm{~min}\right)$ and analyzed in a bioassaymulti105 detection (the USA, plate reader, FLx800-Biotek). Dichlorofluorescein was read at emission 520 $106 \mathrm{~nm}$ and excitation $485 \mathrm{~nm}$. ROS production was detected from a 10-200 nM $\mathrm{H}_{2} \mathrm{O}_{2}$ standard 107 curve.

108 Intracellular calcium $\left(\mathrm{Cai}^{2+}\right)$ measurement

109 Intracellular calcium $\left(\mathrm{Cai}^{2+}\right)$ was determined by Fluo-3-acetoxymethyl ester (Fluo-3/AM, 10 $110 \mathrm{mM}$, Interchim) dissolved in DMSO [18]. Two types of buffer solutions were prepared for 111 washing: buffer 1 (Phenol red-free DMEM containing 10 mM HEPES (4-(2-hydroxyethyl) 112 piperazine-1- ethane sulfonic acid, pH7.0) and buffer 2 [DMEM containing 10-mM HEPES, 
$1135 \%$ fetal calf serum, and $\mathrm{pH} 7.4)]$. First, aliquots of $1 \mathrm{~mL}$ cell suspensions $\left(1 \times 10^{6}\right.$ cells $\left./ \mathrm{mL}\right)$ 114 were washed and resuspended in buffer 1. Then, $0.4 \mu \mathrm{L}$ of Fluo 3-AM (1.0 M in DMSO) was 115 added and for $30 \mathrm{~min}$, cells at room temperature were incubated and before performing the assay,

116 washed with buffer 2. $\mathrm{Cai}^{2+}$ was analyzed by a FAC scan caliber ${ }^{\mathrm{TM}}$ flow cytometer (USA, 117 California, Becton Dickinson).

118 Investigating the expression of NOX2 and Bax/Bcl-2 ratio by Western Blot

119 The cells were lysed in lysis buffer (20 mMTris- $\mathrm{HCl}, 137 \mathrm{mM} \mathrm{NaCl}(\mathrm{pH} 8.0), 1 \% \mathrm{NP} 40$, 120 glycerol $10 \%$, aprotinin $10 \mu \mathrm{g} / \mathrm{mL}$, phenylmethyl sulfonic fluoride $1 \mathrm{mM}$, sodium vanadate 0.5 $121 \mathrm{mM}$, and leupeptin $1 \mu \mathrm{g} / \mathrm{mL})$. For $20 \mathrm{~min}$, homogenates were centrifuged at $12,500 \mathrm{rpm}\left(4^{\circ} \mathrm{C}\right)$, 122 and then, at $-70^{\circ} \mathrm{C}$ supernatants were stored [19]. Based on the micro BCA kit protocol (USA, 123 Rockford, Pierce. IL), total protein content was measured. Equal protein amounts $(3,000 \mu \mathrm{g})$ 124 from every sample were loaded on gels and electrotransferred to PVDF membranes. Thereafter 125 for $1 \mathrm{~h}$, blocked at room temperature and then, incubated PVDF with primary antibodies 126 followed by appropriate secondary antibodies anti-primary IgG horseradish peroxidase127 conjugated. Using the ECL kit (USA, Piscataway, Biotech Inc., Amersham Pharmacia NJ), 128 according to the manufacturer's instructions, chemiluminescence detection of immunocomplexes 129 was done and by using software (Gel-Pro analyzer, USA, Bio-Rad), the results were quantified. 130 Analysis of protein was done by anti-human ILK (Priab 1/5000, ab-76468, Sec ab 1/2000), 131 VEGF, BDNF (SAB4300702, Sigma,1: 750), NGF (Priab 1/500, ab- P5498, Sigma). (Germany, 132 C-2, Santa Cruz, Heidelberg) at a 1:1000 dilution ratio.

133 Statistical analysis

134 Experiments were repeated at 3 different times. Statistical analyses were performed on different 135 groups using ANOVA and t-tests. All the results were expressed as mean \pm standard deviation. 
136 The term half-maximal lethal concentration (LC 50) refers to a drug or toxicant that induces a

137 response between the baseline and the maximum. $\mathrm{P}$ values of less than 0.05 were considered

138 significant.

139 Results

140 Extraction and identification

141 Thymol Standard was read at a wavelength of $284 \mathrm{~nm}$ with retention time at $5.200 \mathrm{~min}$, and in 142 the same condition, Thymol in TSE had retention time at $5.267 \mathrm{~min}$ (Figure 1a, b). Figure 1 143 showed the peak of Thymol in TSE in comparison to standard Thymol. Quantitative analysis 144 showed that thymol was dominant in every fractionated methanol (Thymol $19.14 \mathrm{mg} / \mathrm{g}$ ) of TSE. 145 All methods were validated and showed a linear calibration curve:

$146 \quad \mathrm{y}=827.68 \mathrm{x}-12599$

$$
\mathrm{R}^{2}=0.9942
$$

147 Effects of Thymol and Thymbra spicata extract on cell viability

148 Figure 2 showed no evidence of cell death in free Thymol or TSE at concentrations of 5, 10, 20, 149 and $40 \mu \mathrm{M}$. However, incubation at high concentrations (180 (18 and 24 vs 100 ,control, $150 * * \mathrm{P}<0.001), 120$ (35 and 41 vs $100, * * \mathrm{P}<0.001)$, and $80 \mu \mathrm{M}(75$ and 82 vs $100,(* \mathrm{P}<0.05))$, 151 with free Thymol or TSE respectively, led to a decrease in cell viability.

\section{Effects of Thymol and Thymbra spicata extract on ROS generation}

153 Treatment with Thymol and $\operatorname{TSE}(5,10,20$, and $40 \mu \mathrm{M})$ did not increase ROS levels in cells. 154 However, free Thymol and TSE at concentrations of 80 (125 and 129 vs. 100, control, $155(* \mathrm{P}<0.05), 120$ (143 and 147 vs. $100, * * \mathrm{P}<0.001)$, and $180(161$ and 182 vs. $100, * * \mathrm{P}<0.001)$ $156 \mu \mathrm{M}$ significantly increased intracellular ROS (Figure 3).

\section{Effects of Thymol and Thymbra spicata extract on intracellular calcium}


$158 \mathrm{Cai}^{2+}$ significantly increased in Thymol and TSE treated samples (180 (137 and 151 vs. 100 159 ,control, $* * \mathrm{P}<0.001), 120$ (128 and 135 vs. $100, * * \mathrm{P}<0.001)$, and $80 \mu \mathrm{M}(115$ and 118 vs. 100 ,

$160(* \mathrm{P}<0.05))$ treated samples. Thymol and TSE at low concentrations of 5, 10, 20, and $40 \mu \mathrm{M}$ did 161 not increase $\mathrm{Cai}^{2+}$ (Figure 4).

162 Effects of Thymol and Thymbra spicata extract on $\mathrm{NOX}_{2}$ protein expression

163 The apoptotic capacity of Thymol and TSE was performed by the $\mathrm{NOX}_{2}$ expression. Notably, a $164 \mathrm{NOX}_{2}$ expression increase has been observed in Thymol and TSE at high concentrations (Figure $1655)$.

166 Effects of Thymol and Thymbra spicata extract on Bax/Bcl-2 ratio expression

167 Finally, the apoptotic capacity of Thymol and TSE was performed by the whole-mount 168 immunofluorescence of Bax/Bcl-2 ratio expression by western blotting analyses. Notably, it was 169 observed a decrease in the expression of the anti-apoptotic (Bcl-2) in line with the Bax 170 expression increasing at high concentrations Thymol and TSE exposed (180 (171 and 192 vs. 171100 , control, $* * \mathrm{P}<0.001), 120$ (153 and 157 vs. $100, * * \mathrm{P}<0.001)$, and $80 \mu \mathrm{M}(135$ and 139 vs. $172100, * * \mathrm{P}<0.001)$ ) (Figure 6).

\section{Discussion}

174 In this study, Thymol present in TSE was induced cell death due to activation of $\mathrm{NOX}_{2}, \mathrm{ROS}$ 175 generation, increase in $\mathrm{Cai}^{2+}$, and $\mathrm{Bax} / \mathrm{Bcl}_{-2}$ ratio. It found that high concentrations of TSE and 176 Thymol in it caused cell death in lung cancer cells. There are some compounds in TSE, among 177 them Thymol was $18.64 \mathrm{mg} / \mathrm{g}$. Previously, It has been shown that $55.35 \%$ of thyme extract was 178 Thymol [20]. But another study documented that the amount of Thymol in Thymbra spicata 179 extract was varying from $0.4-37.5 \%$. Studies showed that agronomic practices under cultivation 
180 conditions, environmental, and genetic had effects on essential oils, chemical compositions, and 181 agronomic characteristics of Thymbra spicata [21].

182 In this study, high concentrations $(80,120$, and $180 \mu \mathrm{M})$ of Thymol and TSE increased the rate 183 of cell death in a concentration-dependent manner. LC 50 values of Thymol and TSE were $184111 \pm 4.5$ and $119 \pm 5.2 \mu \mathrm{M}$, respectively. But, cell death was not observed with low concentrations $185(40,20,10$, and $5 \mu \mathrm{M})$ of Thymol and TSE. In one study, the $\mathrm{LD}_{50}$ value of Thymol for 186 evaluating the human malignant tumor cells was $18.9 \mu \mathrm{M}$ [22]. Also, it was shown that LC50 of 187 Thymol for different cell lines such as T24 and SW280 were 90.1 \pm 7.6 and $108.6 \pm 11.3 \mu \mathrm{M}$, 188 respectively [23]. In another study, it was shown that the $\mathrm{LD}_{50}$ value for Thymbra spicata extract 189 was $109 \pm 4.3 \mu \mathrm{M}[24]$.

190 As reported previously, apoptosis was induced by ROS production in various types of cancer 191 cells [25]. An important source of reactive oxygen species is nicotinamide adenine dinucleotide 192 phosphate (NADPH) Oxidases (NOXs) [26]. Evidence suggests the role of ROS-related 193 signaling in the survival, proliferation, and other phenotypic behaviors of cancer cells [27]. 194 Results of some studies showed that compounds such as aloin inhibit the proliferation and 195 migration of gastric cancer cells by NOX2-ROS-mediated activation of Akt/mTOR, Stat3, and 196 NF- $\mathrm{BB}$ signaling pathways [28]. $\mathrm{NOX}_{2}$, a respiratory burst oxidase, generates $\mathrm{O}_{2}{ }^{--}$in activated 197 neutrophils [29] and is a promising therapeutic target for oxidative stress-related diseases [30]. 198 Our data suggested that high concentrations $(80,120$, and $180 \mu \mathrm{M})$ of Thymol and TSE caused 199 an increase in the generation of $\mathrm{NOX}_{2}$ and ROS as compared to untreated cells during apoptosis. 200 Incubation of cells with low concentrations (40, 20, 10, and $5 \mu \mathrm{M})$ of Thymol and TSE prevented 201 the production of $\mathrm{NOX}_{2}$ and ROS from increasing. An investigation was performed on Korean 202 red ginseng to see if it exerted an anti-inflammatory effect on A549 cells via the suppression of 
203 the generation of ROS and downregulation of NF-kB activation [31]. Moreover, another study,

204 showed that autophagic cell death was induced by Derron through intracellular ROS and stable

205 ERK phosphorylation in A549 cells [32]. In one study, thymoquinone generated cellular ROS,

206 including hydrogen peroxide and superoxide radicals, particularly at a higher concentration (25

$207 \mu \mathrm{M})$. Reactive oxygen species scavenger (NAC (N-acetyl-cysteine)) treatment inhibited

208 thymoquinone-induced Caki-1 cell death, implying cancer cell death through its pro-oxidant

209 property. The main sources of cellular reactive oxygen species comprise the mitochondrial

210 respiratory chain component, XO (xanthine oxidase), and NOXs [33]. Data indicated the efficacy

211 and safety profile of terpenoids of Celastrus orbiculatus, a multi-terpenoid-based remedy against

212 PMA-induced NETosis via NOX signaling pathway, which provided initial evidence for

213 Celastrus orbiculatus as an anti-inflammatory medication [34].

214 Increased intracellular calcium $\left(\mathrm{Cai}^{2+}\right)$ promotes cell death in many different types of cells, 215 including lung cells [35]. Our data indicated that $\mathrm{Cai}^{2+}$ significantly increased for samples treated 216 with Thymol and TSE $(180,120$, and $80 \mu \mathrm{M})$, but low concentrations of 5, 10, 20 and $40 \mu \mathrm{M}$ did

217 not increase $\mathrm{Cai}^{2+}$. The apoptotic effect of Thymol induced a $\left[\mathrm{Cai}^{2+}\right]$ rise in a concentration218 dependent manner in human glioblastoma, osteosarcoma, and renal tubular cells [36-38]. It was 219 shown that there are some cytotoxic effects on lung NCI-H292 cells due to increasing Cai ${ }^{2+}$ 220 induced by ursolic acid, which is a triterpene compound present in natural plants [39]. A study 221 showed that terpenoids in Zingiber officinale (Ginger) caused cell death in endometrial cancer 222 cells by increasing intracellular calcium [40]. Also, it was demonstrated that Asiatic acid, a 223 pentacyclic triterpene isolated from the Centella Asiatica, was successfully tested for its 224 apoptotic effects in HepG2 cells by an increase in intracellular calcium levels [41]. 
225 Bcl-2 proteins often form heterodimer complexes with Bax proteins, which result in the release

226 of cytochrome c from the mitochondria and subsequent induction of cell death [42]. Hence, one

227 of the major markers of pre-apoptosis is an increase in the ratio of Bax/Bcl-2 [43]. In this study,

228 it has been shown that in A549 cells, high concentrations $(180,120$, and $80 \mu \mathrm{M})$ of Thymol and

229 TSE increased $\mathrm{Bax} / \mathrm{Bcl}-2$ ratio protein expression as compared to untreated cells during 230 apoptosis while low concentrations (40, 20, 10 and5 $\mu \mathrm{M})$ of Thymol and TSE did not. It was 231 demonstrated that Thymus Caramanica Jalas (Lamiaceae family), which is one species of 232 Thymus, significantly increased cell damages, activated caspase 3, and Bax/Bcl-2 ratio [44]. 233 Also, Origanum majorana containing phenolic terpenoids (thymol and carvacrol) increased cell 234 death against breast cancer cell lines by increasing the Bax/Bcl-2 ratio [45]. In another study, 235 Thymol showed an increase in Bax protein levels with a concomitant decrease in Bcl2 protein 236 expression in a dose-dependent manner [46]. Also, it has been shown that treatment with the 237 Salvia aurea (Lamiaceae family) led to the activation of pro-apoptotic protein Bax, shifting the $238 \mathrm{Bax} / \mathrm{Bcl}-2$ ratio in favor of apoptosis [47].

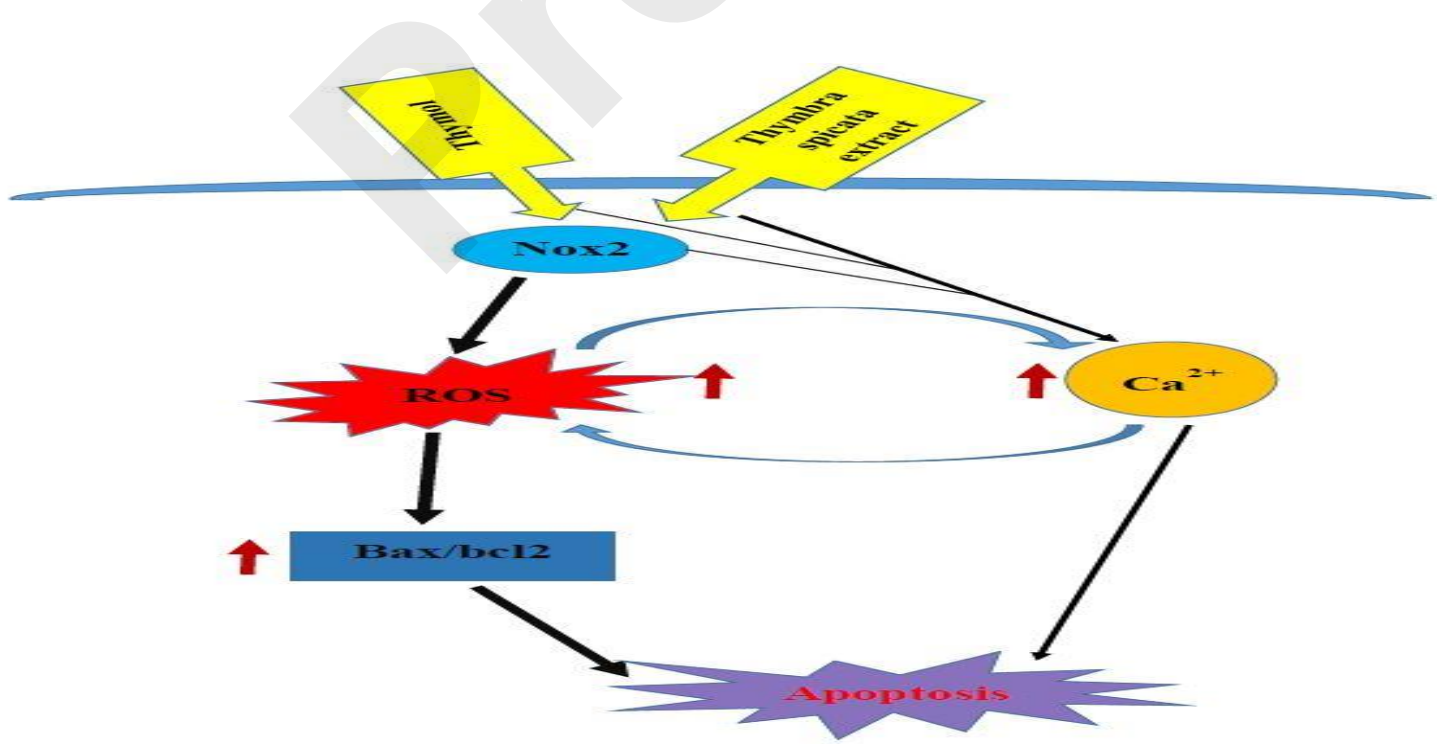




\section{Conclusions}

246 This study focused on the cytotoxicity assay of Thymbra spicata extract (TSE) and its bioactive 247 component, Thymol, on non-small-cells lung cancer A549 and its mechanism of cell death. Our 248 results demonstrated that TSE and Thymol at high concentrations (180, 120, and $80 \mu \mathrm{M})$ 249 decreased the growth of A549 cells. It appeared that cytotoxic activity was exerted through 250 activation of $\mathrm{NOX}_{2}$, ROS generation, increase in $\mathrm{Cai}^{2+}$, and $\mathrm{Bax} / \mathrm{Bcl}-2$ ratio. Present results 251 demonstrated that TSE and thymol may be potential therapeutic agents for human lung cancer.

\section{Acknowledgments}

253 The authors are grateful for the financial and technical support of the Ilam University of Medical 254 Science.

\section{Conflict of interest}

256 None stated.

\section{Authors' contributions}

258 All authors designed the study. AM: designed, took the lead in writing the manuscript, Sh M:

259 contributed to the interpretation of the results, NA: contributed to the interpretation of the 260 results, AA: performed the experiments, $\mathrm{HGH}$ : derived the models and analyzed the data, EK: 261 took the lead in writing the manuscript. All authors have read and approved the manuscript.

\section{Funding}


263 This project with code 961019/103 was approved and supported by the Research Council of 264 Ilam University of Medical Sciences.

\section{References}

266 1. Kaplan, A., G. Akalin Ciftci, and H.M. Kutlu, The apoptotic and genomic studies on A549 cell line induced by silver nitrate. Tumour biology : the journal of the International Society for Oncodevelopmental Biology and Medicine, 2017. 39(4): p. 1010428317695033.

2. Camerlingo, R., et al., Conditioned medium of primary lung cancer cells induces EMT in A549 lung cancer cell line by TGF- $\beta 1$ and miRNA21 cooperation. PloS one, 2019. 14(7): p. e0219597e0219597.

272 3. Lin, M.-L., et al., Rhein induces apoptosis through induction of endoplasmic reticulum stress and Ca2+-dependent mitochondrial death pathway in human nasopharyngeal carcinoma cells. Anticancer research, 2007. 27(5A): p. 3313-3322.

4. Sies, H., Role of metabolic H2O2 generation: redox signaling and oxidative stress. The Journal of biological chemistry, 2014. 289(13): p. 8735-8741.

277 5. Kirkland, R.A., et al., Bax regulates production of superoxide in both apoptotic and nonapoptotic

6. Davis, A.P., et al., The Comparative Toxicogenomics Database: update 2013. Nucleic acids research, 2013. 41(Database issue): p. D1104-D1114.

282 7. Cragg, G. and D. Newman, Natural products: A continuing source of novel drug leads. Biochimica et biophysica acta, 2013. 1830.

284 8. Monteiro, L.d.S., et al., Medicinal Plants and Other Living Organisms with Antitumor Potential

2014: p. 604152-604152. 
287 9. Wang, Z.H., et al., Myricetin suppresses oxidative stress-induced cell damage via both direct and indirect antioxidant action. Environmental toxicology and pharmacology, 2010. 29(1): p. 12-18.

289 10. Ivanovska, N. and S. Philipov, Study on the anti-inflammatory action of Berberis vulgaris root extract, alkaloid fractions and pure alkaloids. Int J Immunopharmacol, 1996. 18(10): p. 553-61.

11. Masraksa, W., et al., Luteolin attenuates migration and invasion of lung cancer cells via 292 suppressing focal adhesion kinase and non-receptor tyrosine kinase signaling pathway. Nutr Res Pract, 2020. 14(2): p. 127-133.

294 12. Sun, Q., et al., Diagnostic Significance of Serum Levels of Nerve Growth Factor and Brain Derived 295

13. Elbe, H., et al., Apoptotic effects of thymol, a novel monoterpene phenol, on different types of cancer. Bratislavske lekarske listy, 2020. 121(2): p. 122-128.

14. López, A., et al., Phenolic constituents, antioxidant and preliminary antimycoplasmic activities of 299 leaf skin and flowers of Aloe vera (L.) Burm. f. (syn. A. barbadensis Mill.) from the Canary Islands

15. Moayeri, A., et al., Attenuation of Morphine Withdrawal Syndrome by Prosopis Farcta Extract and Its Bioactive Component Luteolin in Comparison with Clonidine in Rats. Med Sci Monit Basic Res, 2018. 24: p. 151-158.

16. Yee, S.B., et al., Inhibitory effects of luteolin isolated from Ixeris sonchifolia Hance on the 305 proliferation of HepG2 human hepatocellular carcinoma cells. Arch Pharm Res, 2003. 26(2): p. 151-6.

17. Johnson, J.L. and E. Gonzalez de Mejia, Interactions between dietary flavonoids apigenin or 308 luteolin and chemotherapeutic drugs to potentiate anti-proliferative effect on human pancreatic cancer cells, in vitro. Food Chem Toxicol, 2013. 60: p. 83-91. 
18. Fang, J., et al., Luteolin inhibits insulin-like growth factor 1 receptor signaling in prostate cancer cells. Carcinogenesis, 2007. 28(3): p. 713-23.

19. Cosentino, F., et al., High Glucose Increases Nitric Oxide Synthase Expression and Superoxide Anion Generation in Human Aortic Endothelial Cells. Circulation, 1997. 96(1): p. 25-28.

20. Gedikoglu, A., M. Sokmen, and A. Civit, Evaluation of Thymus vulgaris and Thymbra spicata essential oils and plant extracts for chemical composition, antioxidant, and antimicrobial properties. Food Sci Nutr, 2019. 7(5): p. 1704-1714.

21. Kizil, S., O. Toncer, and E. Diraz, Variation of agronomical characteristics and essential oil components of Zahter (Thymbra Spicata L. var. Spicata) populations in semi-arid climatic conditions. Turkish Journal of Field Crops, 2015. 20: p. 242-151.

22. Rajput, J., et al., Comparative Anti-Proliferative Studies of Natural Phenolic Monoterpenoids on Human Malignant Tumour Cells. Medicinal \& Aromatic Plants, 2016. 5: p. 1-4.

23. Li, Y., et al., Thymol inhibits bladder cancer cell proliferation via inducing cell cycle arrest and apoptosis. Biochem Biophys Res Commun, 2017. 491(2): p. 530-536.

24. Karimi, E., S. Abbasi, and N. Abbasi, Thymol polymeric nanoparticle synthesis and its effects on the toxicity of high glucose on OEC cells: involvement of growth factors and integrin-linked kinase. Drug design, development and therapy, 2019. 13: p. 2513-2532.

25. Kang, S.-H., et al., Anticancer Effect of Thymol on AGS Human Gastric Carcinoma Cells. Journal of microbiology and biotechnology, 2016. 26(1): p. 28-37.

26. Kim, S.Y., et al., Pro-inflammatory hepatic macrophages generate ROS through NADPH oxidase 2 via endocytosis of monomeric TLR4-MD2 complex. Nat Commun, 2017. 8(1): p. 2247.

27. Saikolappan, S., et al., Reactive oxygen species and cancer: A complex interaction. Cancer letters, 2019. 452: p. 132-143. 
28. Wang, Z., et al., Aloin Inhibits the Proliferation and Migration of Gastric Cancer Cells by Regulating NOX2-ROS-Mediated Pro-Survival Signal Pathways. Drug design, development and therapy, 2020. 14: p. 145-155.

29. El-Benna, J., et al., p47phox, the phagocyte NADPH oxidase/NOX2 organizer: structure, phosphorylation and implication in diseases. Experimental \& molecular medicine, 2009. 41(4): p. 217-225.

30. Liu, F.-C., et al., A novel NOX2 inhibitor attenuates human neutrophil oxidative stress and ameliorates inflammatory arthritis in mice. Redox Biology, 2019. 26: p. 101273.

31. Song, H., et al., Korean Red Ginseng suppresses bisphenol A-induced expression of cyclooxygenase-2 and cellular migration of A549 human lung cancer cell through inhibition of reactive oxygen species. Journal of Ginseng Research, 2020.

32. Kang, M.-J., et al., Derrone induces autophagic cell death through induction of ROS and ERK in A549 cells. PloS one, 2019. 14(6): p. e0218659-e0218659.

33. Di Meo, S., et al., Role of ROS and RNS Sources in Physiological and Pathological Conditions. Oxid Med Cell Longev, 2016. 2016: p. 1245049.

34. Tao, L., M. Xu, and Y. Liu, The total terpenoids of Celastrus orbiculatus (TTC) inhibit NOXdependent formation of PMA-induced neutrophil extracellular traps (NETS). European Journal of Inflammation, 2018. 16: p. 205873921880566.

35. Wang, Y., et al., Intracellular calcium promotes radioresistance of non-small cell lung cancer A549 cells through activating Akt signaling. Tumour Biol, 2017. 39(3): p. 1010428317695970.

36. Hsu, S.S., et al., Effect of thymol on Ca2+ homeostasis and viability in human glioblastoma cells. Eur J Pharmacol, 2011. 670(1): p. 85-91.

37. De La Chapa, J.J., et al., Thymol inhibits oral squamous cell carcinoma growth via mitochondriamediated apoptosis. J Oral Pathol Med, 2018. 47(7): p. 674-682. 
38. Chang, H.T., et al., Effects of Thymol on Ca(2)(+) Homeostasis and Apoptosis in MDCK Renal Tubular Cells. Chin J Physiol, 2014. 57(2): p. 90-8.

39. Chen, C.-J., et al., Ursolic Acid Induces Apoptotic Cell Death Through AIF and Endo G Release Through a Mitochondria-dependent Pathway in NCl-H292 Human Lung Cancer Cells In Vitro. In vivo (Athens, Greece), 2019. 33(2): p. 383-391.

40. Liu, Y., et al., Terpenoids from Zingiber officinale (Ginger) induce apoptosis in endometrial cancer cells through the activation of p53. PLoS One, 2012. 7(12): p. e53178.

41. Lee, Y.S., et al., Asiatic acid, a triterpene, induces apoptosis through intracellular Ca2+ release and enhanced expression of p53 in HepG2 human hepatoma cells. Cancer Lett, 2002. 186(1): p. 83-91.

42. Hoetelmans, R.W.M., et al., Bcl-2 and Bax proteins are present in interphase nuclei of mammalian cells. Cell death and differentiation, 2000. 7: p. 384-92.

43. Tasyriq, M., et al., 7alpha-Hydroxy-beta-Sitosterol from Chisocheton tomentosus Induces Apoptosis via Dysregulation of Cellular Bax/Bcl-2 Ratio and Cell Cycle Arrest by Downregulating ERK1/2 Activation. Evid Based Complement Alternat Med, 2012. 2012: p. 765316.

44. Esmaeili-Mahani, S., F. Falahi, and M.M. Yaghoobi, Proapoptotic and Antiproliferative Effects of Thymus caramanicus on Human Breast Cancer Cell Line (MCF-7) and Its Interaction with Anticancer Drug Vincristine. Evid Based Complement Alternat Med, 2014. 2014: p. 893247.

45. Al Dhaheri, Y., et al., Mitotic arrest and apoptosis in breast cancer cells induced by Origanum majorana extract: upregulation of TNF-alpha and downregulation of survivin and mutant p53. PLoS One, 2013. 8(2): p. e56649.

46. Deb, D.D., et al., Effect of thymol on peripheral blood mononuclear cell PBMC and acute promyelotic cancer cell line HL-60. Chem Biol Interact, 2011. 193(1): p. 97-106. 
47. Russo, A., et al., Involvement of Bax and Bcl-2 in Induction of Apoptosis by Essential Oils of Three Lebanese Salvia Species in Human Prostate Cancer Cells. Int J Mol Sci, 2018. 19(1).

\section{Legends of figures}

Figure 1. Standard Thymol (a) and extract of Thymbra spicata (b) HPLC chromatogram. The states were the same for both Thymol and extract of Thymbra spicata.

Figure 2. Thymol and TSE concentrations effects on A549 cell viability. Cells were treated with different concentrations of Thymol and TSE for $48 \mathrm{~h}$, and by the MTT method, cytotoxicity was determined $(* \mathrm{P}<0.05$ vs control, $* * \mathrm{P}<0.001$ vs control).

Figure 3. Thymol and TSE concentrations affect the ROS generation in A549 cells. DCF relative 391 fluorescence was determined at excitation $485 \mathrm{~nm}$ and emission $520 \mathrm{~nm}(* \mathrm{P}<0.05$ vs control, $392 * * \mathrm{P}<0.001$ vs control).

393 Figure 4. Effects of different concentrations of Thymol and TSE on intracellular calcium $394\left(\mathrm{Cai}^{2+}\right) .(* \mathrm{P}<0.05$ vs control, $* * \mathrm{P}<0.001$ vs control $)$.

395 Figure 5. Effect of Thymol and TSE on $\mathrm{NOX}_{2}$ in A549 cells. $\mathrm{NOX}_{2}$ expression (\%) in exposed 396 A549 cells to TSE (NOX E) and Thymol (NOX T). Data are shown as mean \pm SEM.

397 Figure 6. Effect of Thymol and TSE on the Bax/Bcl-2 ratio in A549 cells. Bax expression (\%) in 398 A549 cells exposed to TSE (BAX E), Thymol (BAX T), and Bcl-2 expression (\%) in A549 cells 399 exposed to TSE (Bcl-2 E), Thymol (Bcl-2 T). Data are shown as mean \pm SEM. 400 401 


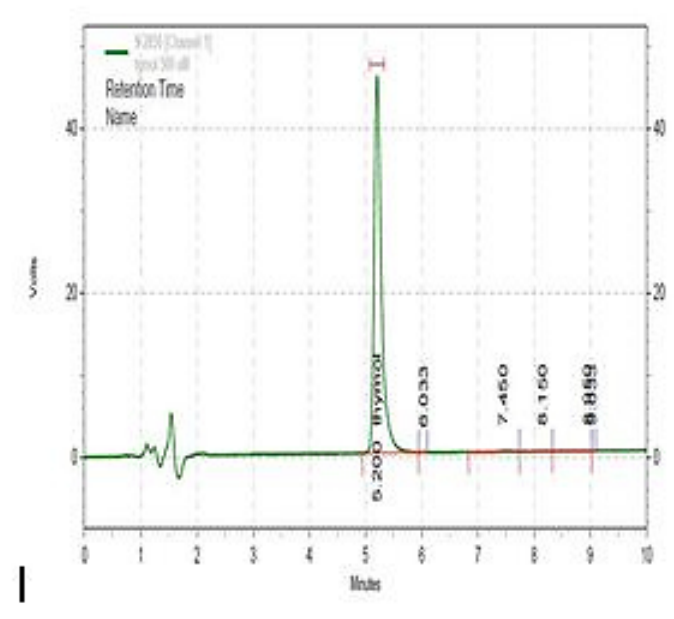

a

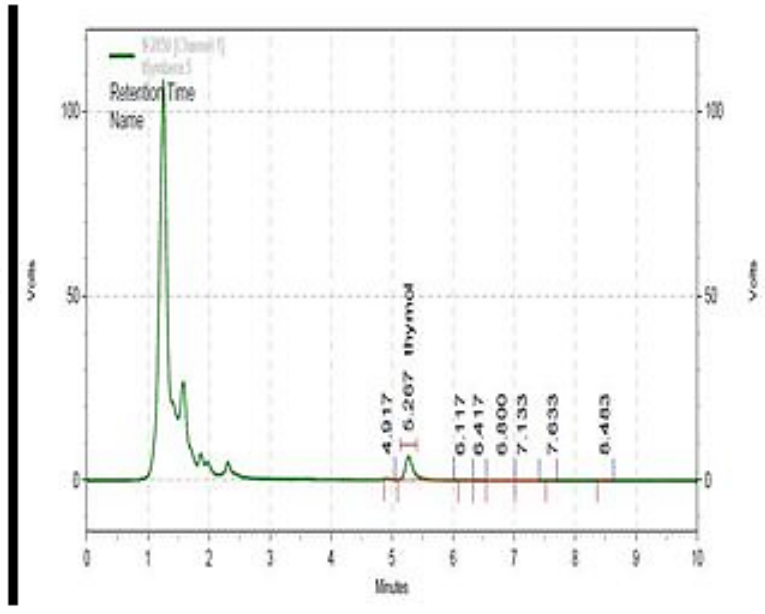

b

Figure 1. Standard Thymol (a) and extract of Thymbra spicata (b) HPLC chromatogram. The states were the same for both Thymol and extract of Thymbra spicata. 


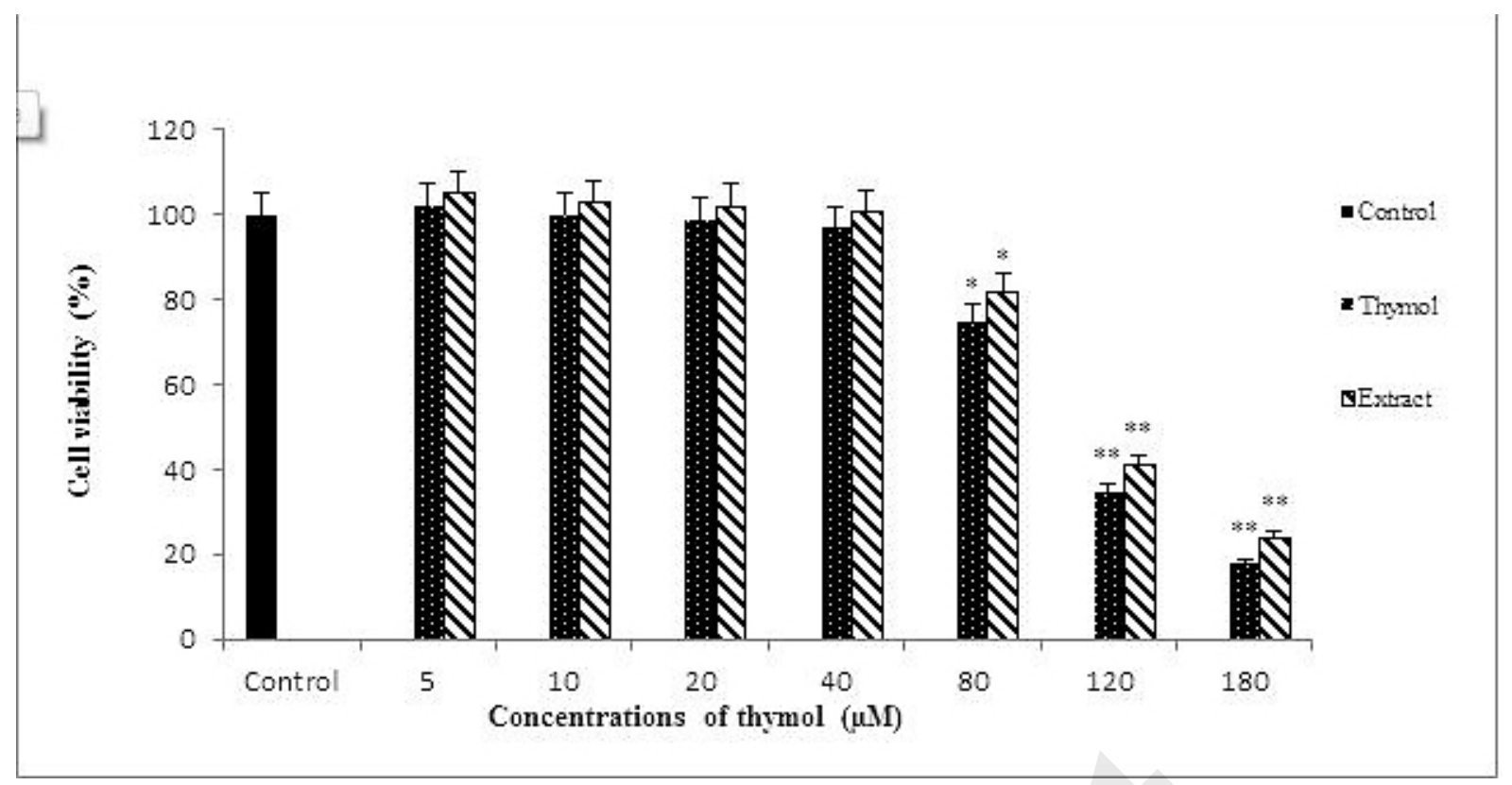

Figure 2. Thymol and TSE concentrations effects on A549 cell viability. Cells were treated with different concentrations of Thymol and TSE for $48 \mathrm{~h}$, and by the MTT method, cytotoxicity was determined ( ${ }^{*} P<0.05$ vs control, ${ }^{* *} \mathrm{P}<0.001$ vs control). 


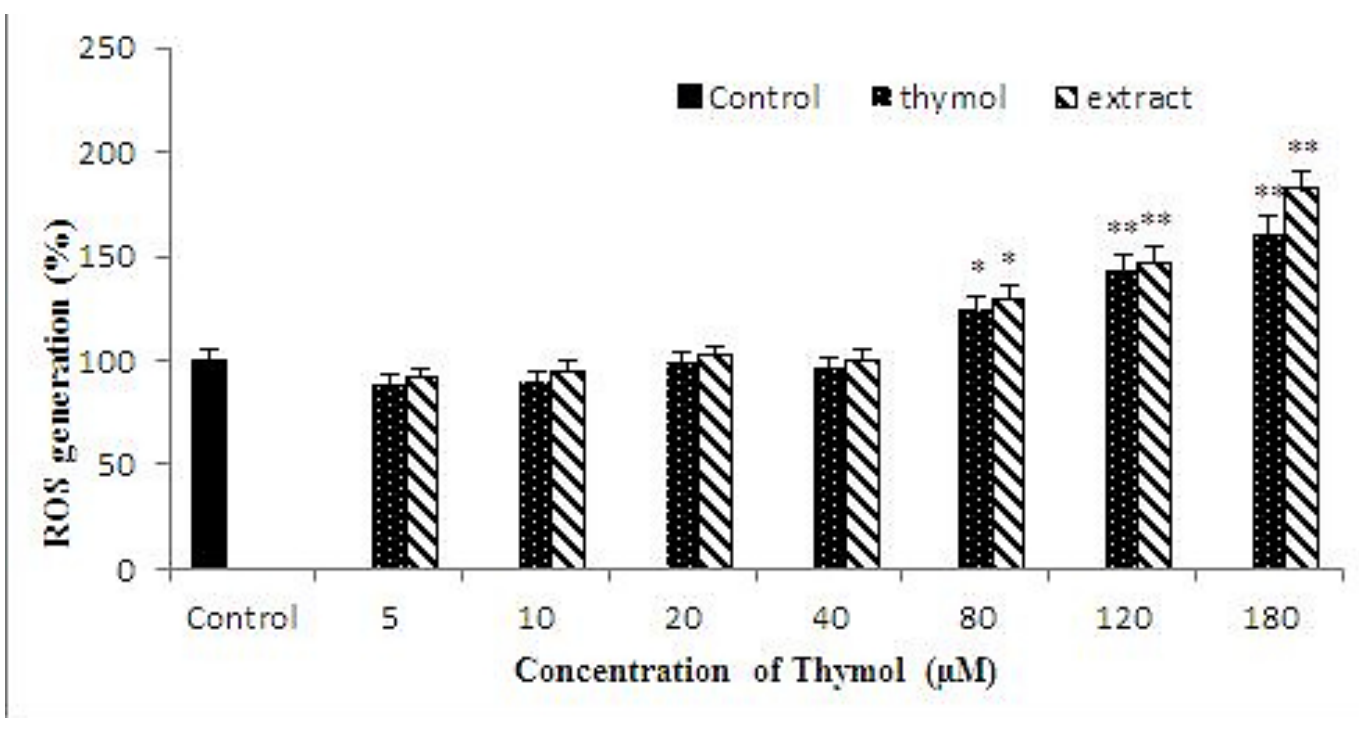

Figure 3. Thymol and TSE concentrations affect the ROS generation in A549 cells. DCF relative fluorescence was determined at excitation $485 \mathrm{~nm}$ and emission $520 \mathrm{~nm}\left({ }^{*} \mathrm{P}<0.05\right.$ vs control, ${ }^{* *} \mathrm{P}<0.001$ vs control). 


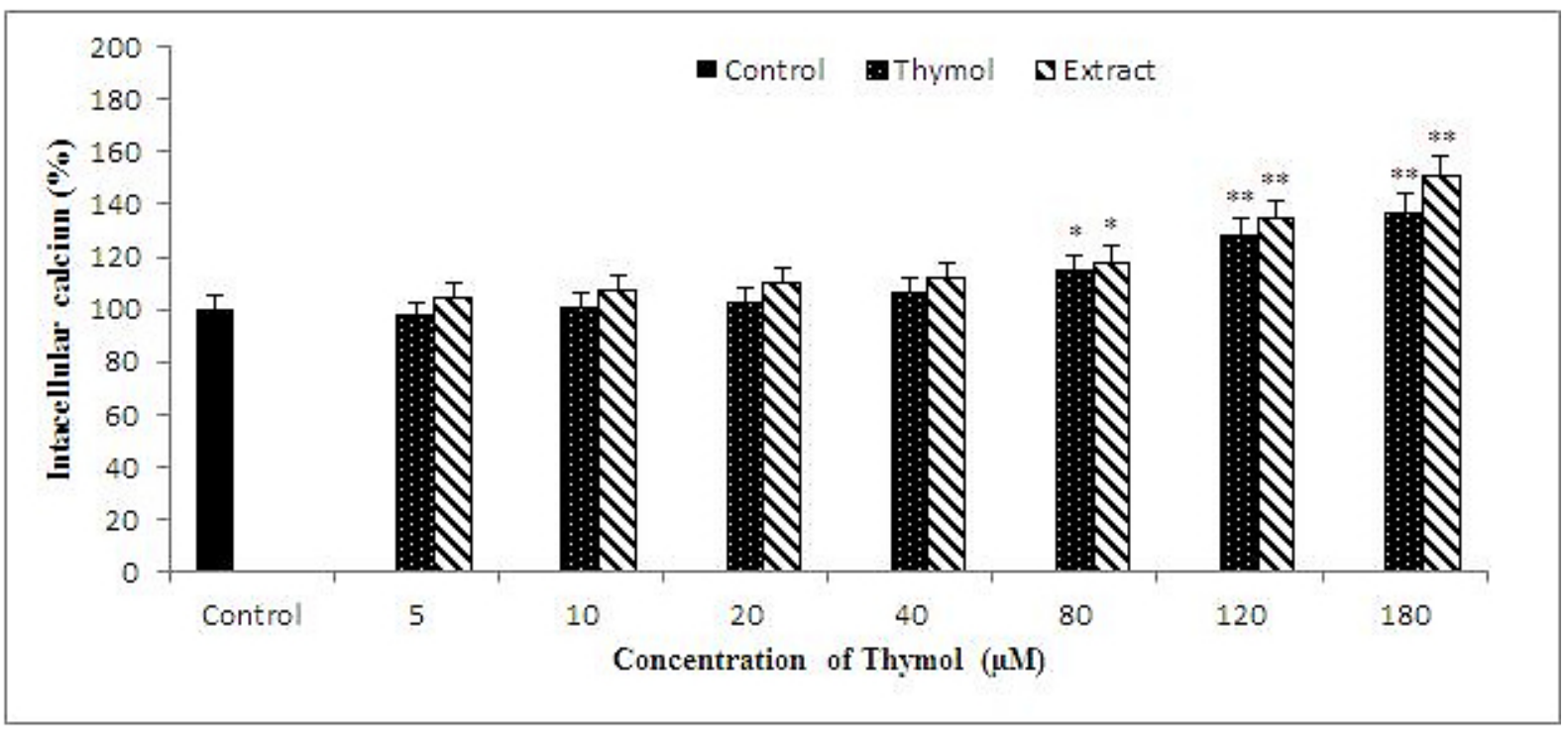

Figure 4. Effects of different concentrations of Thymol and TSE on intracellular calcium (Cai2+). ( ${ }^{*} \mathrm{P}<0.05$ vs control, ${ }^{* *} \mathrm{P}<0.001$ vs control). 

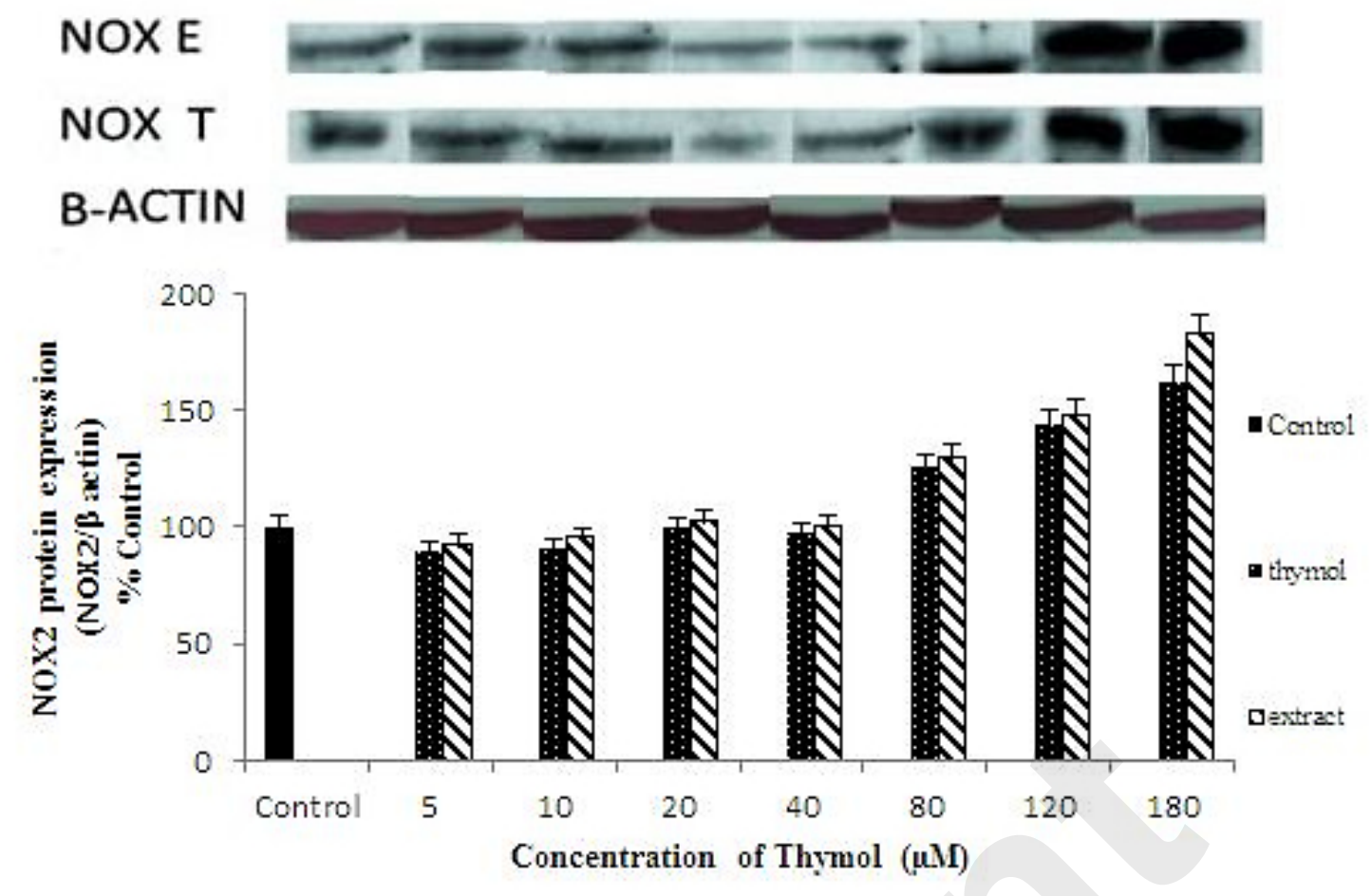

Figure 5. Effect of Thymol and TSE on NOX2 in A549 cells. NOX2 expression (\%) in exposed A549 cells to TSE (NOX E) and Thymol (NOX T). Data are shown as mean \pm SEM. 


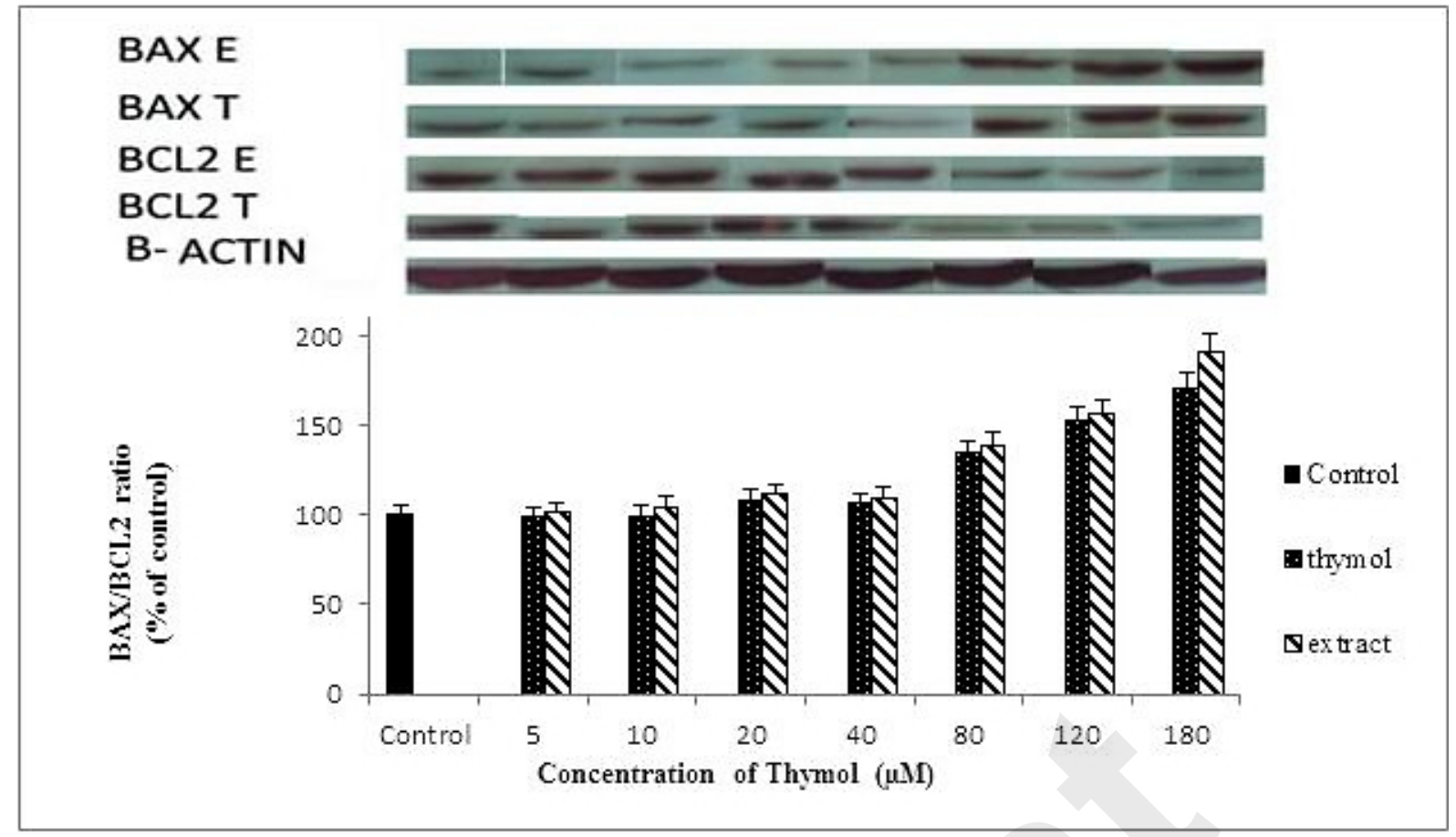

Figure 6. Effect of Thymol and TSE on the Bax/Bcl-2 ratio in A549 cells. Bax expression (\%) in A549 cells exposed to TSE (BAX E), Thymol (BAX T), and Bcl-2 expression (\%) in A549 cells exposed to TSE (Bcl-2 E), Thymol (Bcl-2 T). Data are shown as mean \pm SEM. 